\title{
Methods to Minimize Optical Noise That Degrade Fluorescence Efficiency of Optical Probe for Near-Infrared Tracking in Surgical Environment
}

\author{
Hyeong Ju Park ${ }^{1,2}$, In Hee Shin1, Jae Seok Park1, Joo Beom Eom¹, Seok-Ki Kim³, \\ Byeong-Il Lee ${ }^{1^{*}}$ \\ ${ }^{1}$ Medical Photonics Research Center, Korea Photonics Technology Institute, Gwangju, South Korea \\ ${ }^{2}$ Interdisciplinary Program of Biomedical Engineering, Chonnam National University, Gwangju, South Korea \\ ${ }^{3}$ Department of Nuclear Medicine, National Cancer Center, Goyang, South Korea \\ Email: hi202@kopti.re.kr, ihshin@kopti.re.kr, js89805@gmail.com, jbeom@kopti.re.kr, skim@ncc.re.kr, \\ bilee@kopti.re.kr
}

Received 23 December 2014; accepted 13 January 2015; published 19 January 2015

Copyright (C) 2015 by authors and Scientific Research Publishing Inc.

This work is licensed under the Creative Commons Attribution International License (CC BY).

http://creativecommons.org/licenses/by/4.0/

(c) (i) Open Access

\begin{abstract}
In the medical field, there are growing interests in applied research such as in vivo fluorescence monitoring because of excellent body transmission characteristic of the near-infrared light. However, optical noise by excitation light and illumination equipment for medical applications such as interior light, surgical light decrease efficiency of the fluorescent signal when observers such as surgeons confirm fluorescence signals in medical field. To solve these problems in medical field, we have analyzed external noise factors by effect on image realization, quantification of optical noise generation by external factors, and have suggested methods of minimize the optical noise in this paper. In case of fluorescence imaging in the operating room, it has been confirmed that fluorescent excitation light, interior light and surgical light are factors to generate optical noise. To acquire near-infrared fluorescence images and to compare fluorescence contrast under conditions of darkroom, interior light and surgical light, light emitting diodes (LEDs) sources that have peak wavelength at 740, 760 and $780 \mathrm{~nm}$ respectively were used as excitation light sources. In addition, short-pass filter which has transmission edge at $775 \mathrm{~nm}$ has been applied to minimize the optical noise in each external noise factor. By comparing contrast of each image before and after use of the short-pass filter, we confirmed that optical noise reduced $49 \%, 56 \%$ and $66 \%$ in external noise factors respectively.
\end{abstract}

${ }^{*}$ Corresponding author.

How to cite this paper: Park, H.J., et al. (2015) Methods to Minimize Optical Noise That Degrade Fluorescence Efficiency of Optical Probe for Near-Infrared Tracking in Surgical Environment. J. Biomedical Science and Engineering, 8, 56-65.

http://dx.doi.org/10.4236/jbise.2015.81006 


\section{Keywords}

\section{Near-Infrared, Fluorescence, Optical Noise, Filtering}

\section{Introduction}

Fluorescence imaging technique uses the emission of light by a substance that has absorbed light or other electromagnetic radiation. In most cases, the emitted light has a longer wavelength, and therefore lower energy, than the absorbed radiation. However, fluorescence imaging technique has many advantages such as high contrast, that is, signal to noise ratio (SNR), high sensitivity and simple optical instrumentation and so on [1]-[5].

Recently, near-infrared (NIR) fluorescence monitoring in the range of $700-900 \mathrm{~nm}$ is being utilized in the bio-medical field actively because NIR has high penetration characteristic in hemoglobin, water and lipid etc. [6]-[9].

In addition, Indocyanine green (ICG) which emits NIR light (center wavelength: $830 \mathrm{~nm}$ ) has been used in target protein application since ICG was granted to use in clinical research by Food and Drug Administration (FDA) [10]-[14].

In particular, ICG is applied to monitor lymph nodes and blood vessels pertaining to evaluation of cerebral blood flow, liver, and circulation function because of the low toxicity and the high absorption rate of ICG in range of 600 - $900 \mathrm{~nm}$ [15] [16]. Also, ICG is widely used as the synthesized probe and the surgical guide by NIR fluorescence agent and specific substance which is capable of tracking of tumors [17] [18].

Additionally, Beth Israel Deaconess Medical Center in USA and Hamamatsu in Japan developed FLARE ${ }^{\mathrm{TM}}$ (Fluorescence-assisted resection and exploration) system and PDE (Photodynamic Eye), respectively. They have used the devices to image identification of the sentinel lymph node (SLN) and the metastasis of malignant tumors like the breast cancer and the stomach cancer [19]-[22].

Although preclinical/clinical studies with the NIR fluorescence imaging system have briskly proceeded, studies to improve performance of the NIR fluorescence imaging such as elimination of optical noise, improvement of optical source etc have not briskly proceeded.

Especially, optical noise decreases NIR fluorescence image quality because optical noise reduces effectiveness of NIR fluorescence signals and disturbs detection of minute signals in preclinical/clinical studies. In order to minimize optical noise realized fluorescence image in a dark room. So, studies to minimize optical noise in NIR fluorescence imaging should be considered in preclinical/clinical environment necessarily.

In this paper, we suggest conditions to minimize optical noise by the fluorescent light source, the interior light and the surgical light in the operation room.

\section{Materials and Methods}

\subsection{Composition of a NIR Fluorescence Imaging System}

A NIR fluorescence imaging system was configured to know how optical noise factors influence during realization of NIR fluorescence imaging as shown in Figure 1.

A band-pass filter (\#84-107, Edmund Optics) with $832 \mathrm{~nm} \pm 20 \mathrm{~nm}$ bandwidth and a charge-coupled device (CCD) camera (Guppy Pro F-031B, Allied Vision Technology) with a small lens (\#58-000, Edmund Optics) were used in the fluorescence imaging system.

In addition, an optical light source composed of 16 light emitting diodes (LEDs) with each $1 \mathrm{~W}$ optical power for fluorescence excitation was used in the fluorescence imaging system. Three kinds of LEDs which have the center wavelength of 740, 760 and $780 \mathrm{~nm}$ were prepared for comparison of fluorescence signals according to the wavelengths of the LEDs.

\subsection{Reagent}

For the expression of the NIR fluorescence ICG (Diagnogreen, DAIICHISANKYO CO., Osaka, Japan) with the maximum absorption at $780 \mathrm{~nm}$ and the maximum emission at $830 \mathrm{~nm}$ was resuspended in $10 \mathrm{cc}$ of sterile water to yield a $0.8 \mu \mathrm{l} / \mathrm{ml}$ stock solution. 


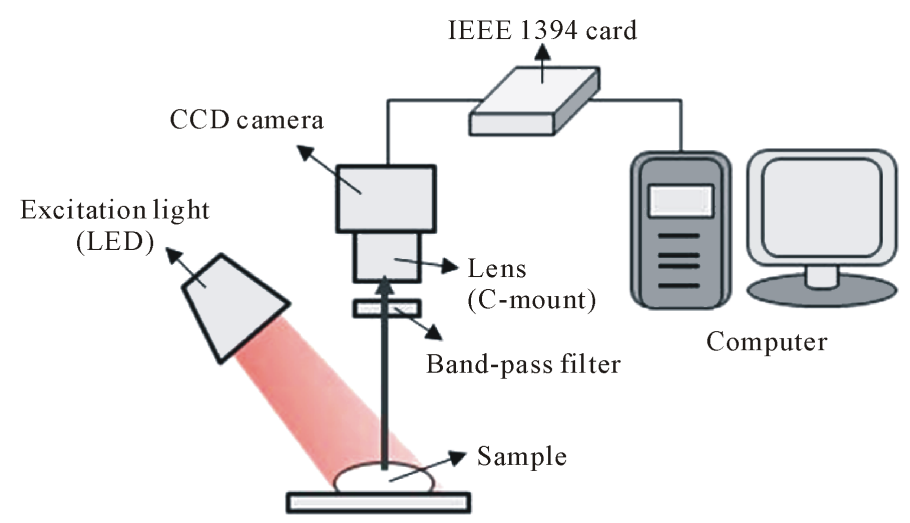

Figure 1. Schematic of NIR fluorescence imaging system.

A circular gauze coated with ICG solution (10 mm in diameter) which was put on a circular gauze without ICG solution (30 $\mathrm{mm}$ in diameter) was prepared as a sample for measurement of the NIR fluorescence.

\subsection{Selection of Optical Noise Environment Factor}

The fluorescence light source, the interior light and the surgical light were selected as optical noise factors in NIR fluorescence imaging.

Most of all, spectra or the fluorescent light source, the interior light and the surgical light that were selected as optical noise factors were measured to verify influence of the factors on optical noise. The NIR fluorescence images under three optical noise factors were acquired and the acquisitions repeated after applying a short-pass filter to minimize optical noise.

\subsubsection{Evaluation of the Properties of Fluorescence Excitation Light and External Lighting}

Spectra of three kinds of LEDs with center wavelength of 740, 760, $780 \mathrm{~nm}$, the interior light and surgical light were measured by using a spectrometer (USB 4000, Ocean Optics).

Measurement results represent as shown in Figure 2.

\subsubsection{Measurement and Analysis of Optical Noise Environment}

First, NIR fluorescence imaging proceeded with three kinds of LEDs in the darkroom in order to verify optical noise effects of the LEDs, excitation light sources.

Second, NIR fluorescence imaging proceeded with three kinds of LEDs under the interior light in order to verify optical noise effects of the interior light.

Finally, NIR fluorescence imaging proceeded with three kinds of LEDs under the surgical light (C100, 1700 lux, Luvis, Korea) in order to verify optical noise effects of the surgical light.

In the NIR fluorescence imaging, we controlled output powers of 740, 760 and $780 \mathrm{~nm}$ LEDs as $270 \mu \mathrm{W}$, respectively. Then, we acquired NIR fluorescence imaging with the circular gauze sample.

For comparison among the NIR fluorescence images obtained under the each condition drawing, we calculated the average value in a region of interest (ROI) of the images. Figure 3 shows application of any circular ROI on the sample by using the ImageJ, an image processing program developed by the United States National Institutes of Health.

Then, we compared the contrast defined as Equation (1) by the expression of fluorescence signal ( $\mathrm{I}_{\mathrm{FS}}$, FS: fluorescence signal) intensity and background signal ( $\mathrm{I}_{\mathrm{BS}}$, BS: background signal) intensity in the NIR fluorescence image.

$$
C=\frac{I_{F S}-I_{B S}}{I_{F S}+I_{B S}}
$$

\subsubsection{The Application of a Short-Pass Filter for Minimum Optical Noise and Method of Analysis} $775 \mathrm{~nm}$ short-pass filter (\#64-615, Edmund Optics) having the optical characteristics as shown in Figure 4 was 


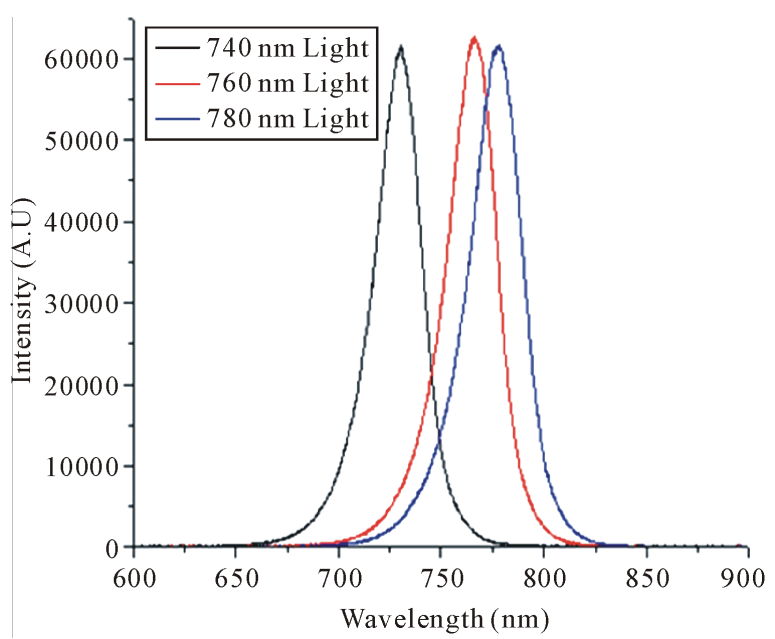

(a)

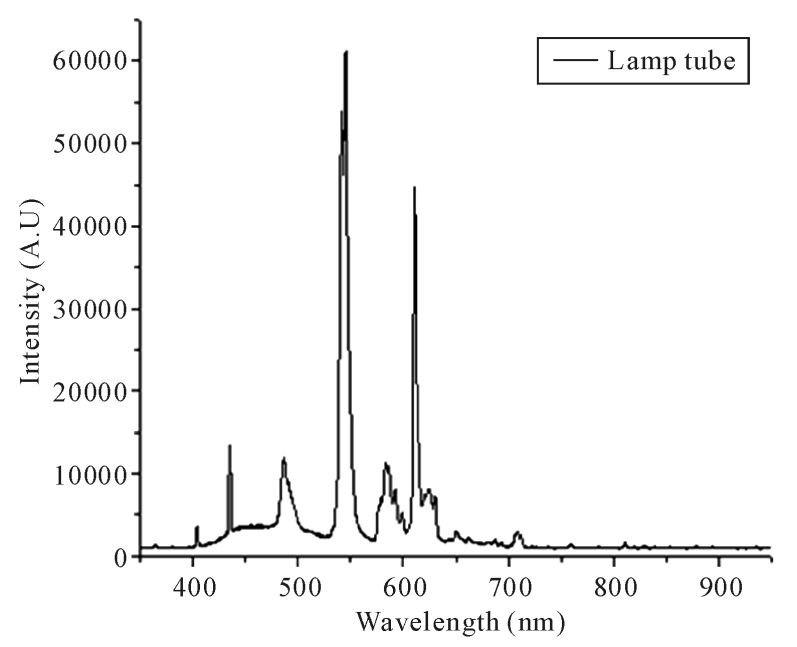

(b)

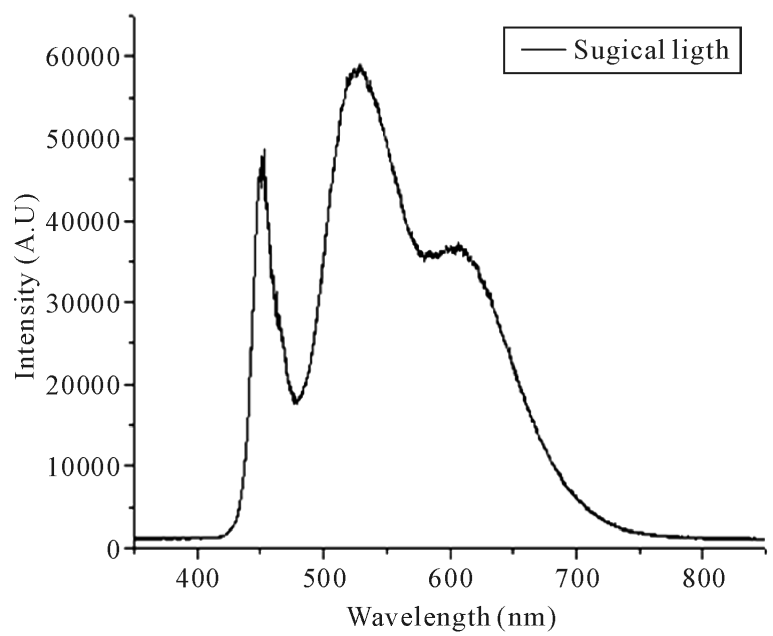

(c)

Figure 2. Emission spectrum curves of each light source. Curves of 740, 760, $780 \mathrm{~nm}$ excitation lights (a), curve of fluorescent light (b), curve of surgical light (c).

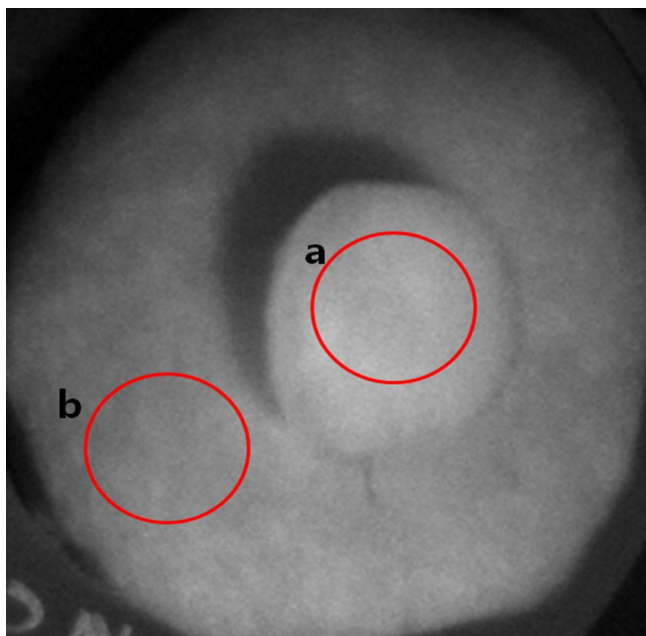

Figure 3. Method of drawing ROI (region of interest). Region of fluorescence signal (a) and background signal (b). 


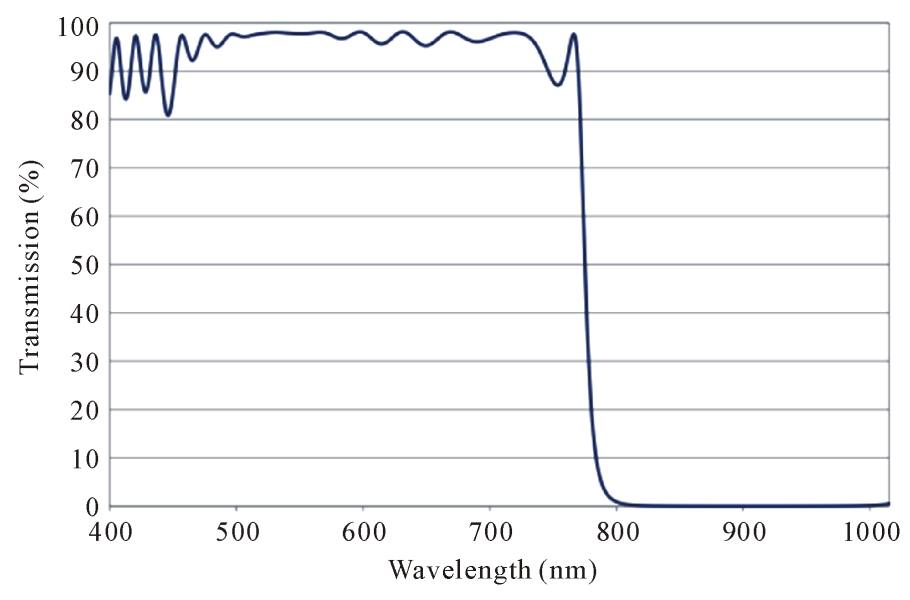

Figure 4. Optical property of $775 \mathrm{~nm}$ short-pass filter.

used to the minimized optical noise by the optical noise factors.

First, we measured spectrum of the fluorescent light source after applying the short-pass filter to the fluorescent light source having a center wavelength of 740,760 and $780 \mathrm{~nm}$ in the darkroom. Also we obtained the fluorescence image of the gauze sample by using the three light sources with the short-pass filter.

Second, we applied the short-pass filter to the interior light and the fluorescent light sources having a center wavelength of 740,760 and $780 \mathrm{~nm}$.

Then, we measured spectrum of the interior light and obtained the fluorescence image of the gauze sample by using the three light sources with the short-pass filter under the interior light with the short-pass filter.

Third, we applied the short-pass filter to the surgical light and the fluorescent light sources having a center wavelength of 740,760 and $780 \mathrm{~nm}$.

Then, we measured spectrum of the surgical light and obtained the fluorescence image of the gauze sample by using the three light sources with the short-pass filter under the surgical light with the short-pass filter.

Finally, we obtained average signals about two regions shown in Figure 3 with the same analysis method of optical noise factor and compared the change of the contrast in Equation (1), by application of the short-pass filter.

\section{Results}

\subsection{Measurement Results of Light Source Properties}

Spectral measurement results of each excitation light source showed that LED light sources with center wavelength of 760 and $780 \mathrm{~nm}$ except for LED light source with center wavelength of $740 \mathrm{~nm}$ have spectral region more than $810 \mathrm{~nm}$. Therefore, it was confirmed that there is overlap between spectrum of light sources with center wavelength of 760 and $780 \mathrm{~nm}$ and emission spectrum of ICG.

In addition, spectral measurement results of the interior light and the surgical light show that they have spectral region more than $810 \mathrm{~nm}$ although optical intensity at the spectral region is minute.

For analysis of optical noise in fluorescence imaging, output power of excitation light sources with center wavelength of 740, 760 and $780 \mathrm{~nm}$ was identically prepared as $270 \mu \mathrm{W}$ and output power of the surgical light output power was prepared to control as $0.85,1.08,1.81,2.41,3.14$ and $3.68 \mathrm{~mW} / \mathrm{cm}^{2}$.

\subsection{Measurement and Analysis Results of Light Noise Environment}

To measure and analyze optical noise factors in fluorescence imaging, we acquired NIR fluorescent images by using LED excitation light sources with center wavelength of 740, 760 and $780 \mathrm{~nm}$ in dark room and we repeated NIR fluorescent imaging under a interior light and a surgical light, respectively.

Figure 5 shows fluorescence images of the circular gauze coated with ICG solution measured by using LED excitation light sources with center wavelength of 740, 760 and $780 \mathrm{~nm}$ in the dark room, respectively.

In case of the excitation light source with center wavelength of $740 \mathrm{~nm}$, the fluorescence image had an aver- 
age intensity of 97.67 and contrast of 0.94 in the dark room.

In case of the excitation light sources with center wavelength of 760 and $780 \mathrm{~nm}$, each average intensity increased to 209.17 and 255.0 and each contrast decreased to 0.45 and 0.00 beside case of the excitation light sources with center wavelength of $740 \mathrm{~nm}$.

Figure 6 shows fluorescence images of the circular gauze coated with ICG solution measured by using LED excitation light sources with center wavelength of 740, 760 and $780 \mathrm{~nm}$ under the interior light, respectively.

In case of the excitation light source with center wavelength of $740 \mathrm{~nm}$, the fluorescence image had an average intensity of 113.16 and contrast of 0.75 under the interior light.

In case of the excitation light sources with center wavelength of 760 and $780 \mathrm{~nm}$, each average intensity was 228.79 and 255.0 and each contrast was 0.41 and 0.00 , respectively.

Figure 7 shows fluorescence images of the circular gauze coated with ICG solution measured by using LED excitation light sources with center wavelength of 740, 760 and $780 \mathrm{~nm}$ under the surgical light, respectively.
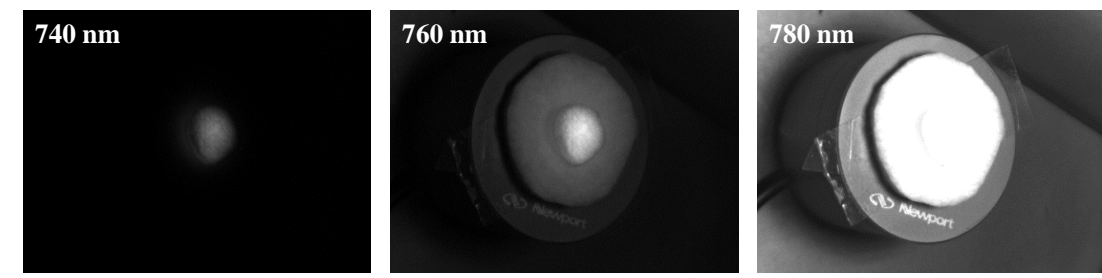

Figure 5. Acquisition of NIR fluorescence imaging using excitation lights (740, 760, $780 \mathrm{~nm}$ ) in the darkroom.
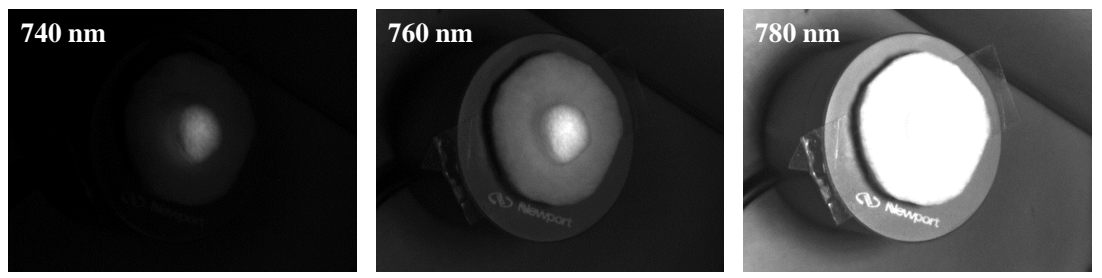

Figure 6. Acquisition of NIR fluorescence imaging using excitation lights (740, 760, $780 \mathrm{~nm}$ ) under the fluorescent light bulb.
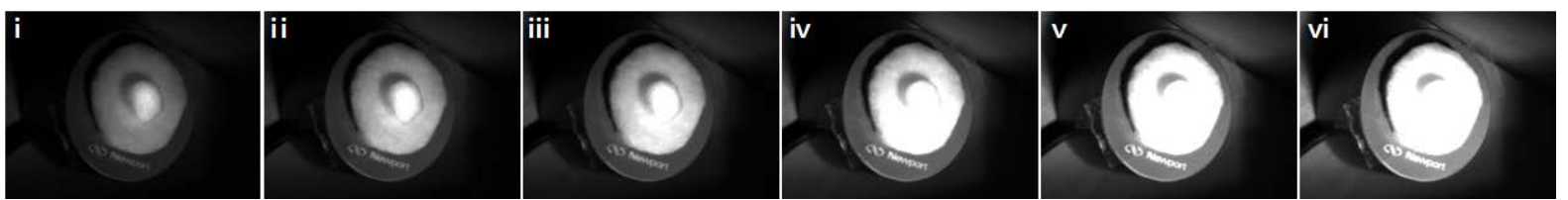

(a)
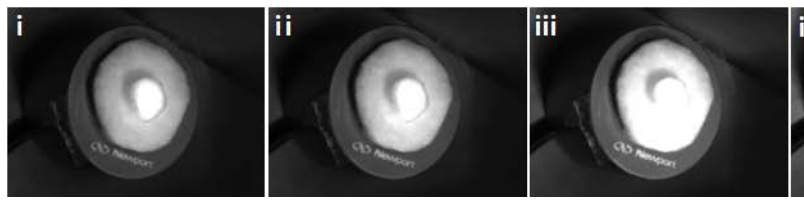

(b)
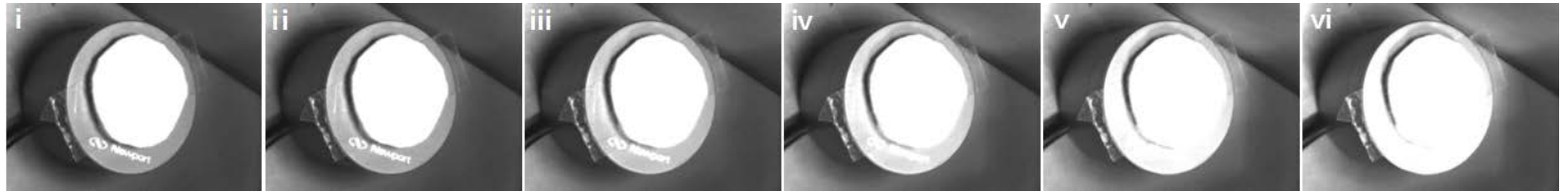

(c)

Figure 7. Acquisition of NIR fluorescence imaging using 740 (a), 760 (b), 780 (c) nm excitation lights under the surgical light (i: in case of $0.85 \mathrm{~mW} / \mathrm{cm}^{2}$; ii: in case of $1.38 \mathrm{~mW} / \mathrm{cm}^{2}$; iii: in case of $2.00 \mathrm{~mW} / \mathrm{cm}^{2}$; iv: in case of $2.47 \mathrm{~mW} / \mathrm{cm}^{2}$; v: in case of $3.28 \mathrm{~mW} / \mathrm{cm}^{2}$; vi: in case of $3.66 \mathrm{~mW} / \mathrm{cm}^{2}$ of surgical light output power). 
The fluorescence images were saturated from $1.81 \mathrm{~mW} / \mathrm{cm}^{2}$ intensity in case of the excitation light source with center wavelength of $740 \mathrm{~nm}$ and were saturated from $0.85 \mathrm{~mW} / \mathrm{cm}^{2}$ intensity in case of the excitation light source with center wavelength of 760 and $780 \mathrm{~nm}$ under the surgical light.

\subsection{Improvement of Optical Noise by Short-Pass Filter}

\section{Improvement Results of Optical Noise by Using Short-Pass Filter}

We placed the short-pass filter in front of excitation light sources (740, 760 and $780 \mathrm{~nm}$ ) and acquired fluorescence images of the circular gauze coated with ICG solution by using LED excitation light sources with center wavelength of 740, 760 and $780 \mathrm{~nm}$ in the dark room, respectively. Figure 8 shows the acquired fluorescence images in the darkroom.

Average fluorescence intensity from each fluorescent image was 77.52 (in case of the $740 \mathrm{~nm}$ light source), 87.83 (in case of the $760 \mathrm{~nm}$ light source), 103.74 (in case of the $780 \mathrm{~nm}$ light source) and each contrast was 0.97 (in case of the $740 \mathrm{~nm}$ light source), 0.97 (in case of the $760 \mathrm{~nm}$ light source), 0.97 (in case of the $780 \mathrm{~nm}$ light source). We could confirm that each optical noise decreased 3\% (in case of the $740 \mathrm{~nm}$ light source), 49\% (in case of the $760 \mathrm{~nm}$ light source), 93\% (in case of the $780 \mathrm{~nm}$ light source) by using the short-pass filter, respectively.

In addition, we placed the short-pass filter in front of excitation light sources $(740,760$ and $780 \mathrm{~nm})$ and the interior light and then we acquired fluorescence images of the circular gauze coated with ICG solution by using LED excitation light sources with center wavelength of 740, 760 and $780 \mathrm{~nm}$ under the interior light, respectively. Figure 9 shows the acquired fluorescence images under the interior light. Average fluorescence intensity from each fluorescent image was 68.28 (in the case of the $740 \mathrm{~nm}$ light source), 84.79 (in the case of the $760 \mathrm{~nm}$ light source), 93.75 (in the case of the $780 \mathrm{~nm}$ light source) and each contrast was obtained 0.94 (in the case of the $740 \mathrm{~nm}$ light source), 0.94 (in the case of the $760 \mathrm{~nm}$ light source), 0.95 (in the case of the $740 \mathrm{~nm}$ light source). We could confirm that each optical noise decreased 20\% (in the case of the $740 \mathrm{~nm}$ light source), $51 \%$ (in the case of the $760 \mathrm{~nm}$ light source), $93 \%$ (in the case of the $780 \mathrm{~nm}$ light source) by using the short pass filter, respectively.

Finally, we placed the short-pass filter in front of excitation light sources (740, 760 and $780 \mathrm{~nm})$ and the interior light and then we acquired fluorescence images of the circular gauze coated with ICG solution by using LED excitation light sources with center wavelength of 740, 760 and $780 \mathrm{~nm}$ under the surgical light, respectively. Figure 10 shows the acquired fluorescence images under the surgical light.

From Figure 7(c) (in the case of the $780 \mathrm{~nm}$ light source), we could confirm that it was impossible to distinguish the background from the fluorescence at $0.85 \mathrm{~mW} / \mathrm{cm}^{2}$ power of surgical light when the short-pass filter did not refer to the light source and the surgical light. From Figure 10(c), on the other hand, we could confirm
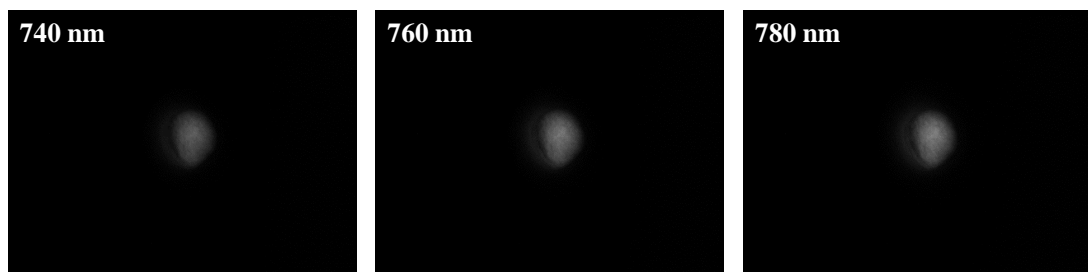

Figure 8. Short-pass filter is applied to excitation light, and then NIR fluorescence imaging acquires in darkroom.
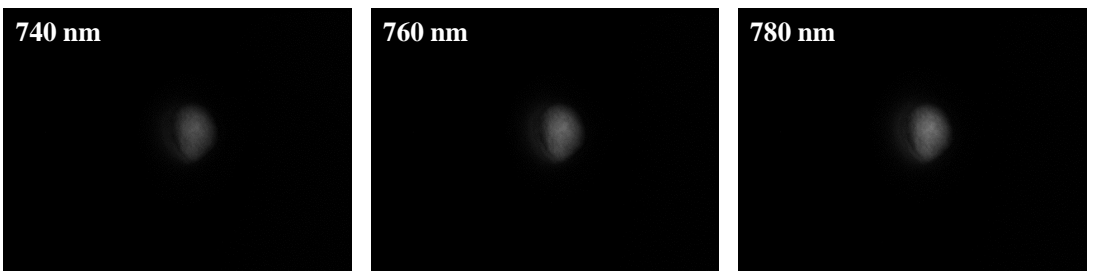

Figure 9. Short-pass filter is applied to excitation light and fluorescent light, and then NIR fluorescence imaging acquires. 

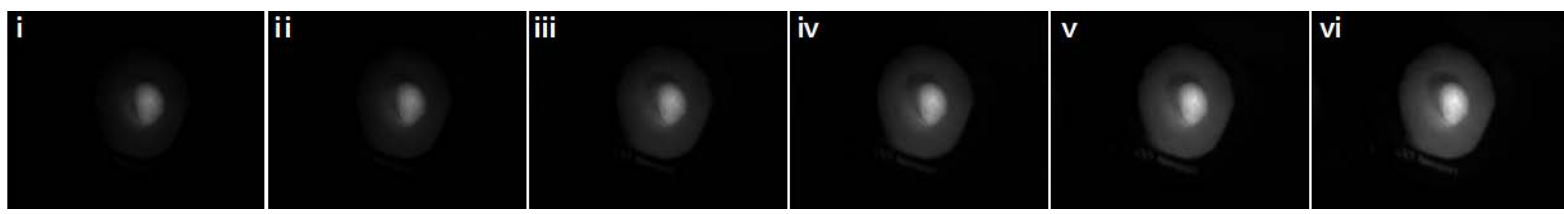

(a)
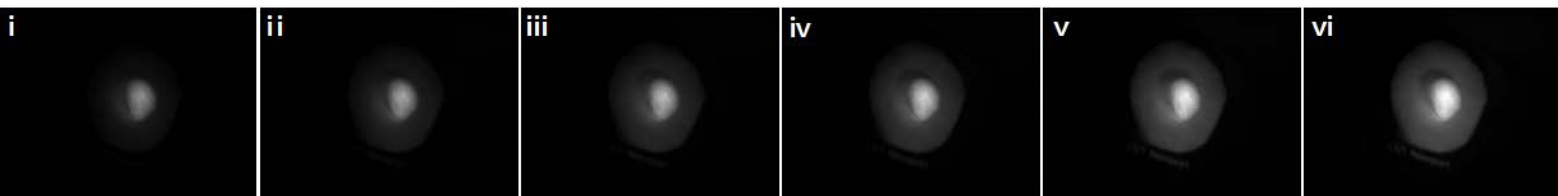

(b)
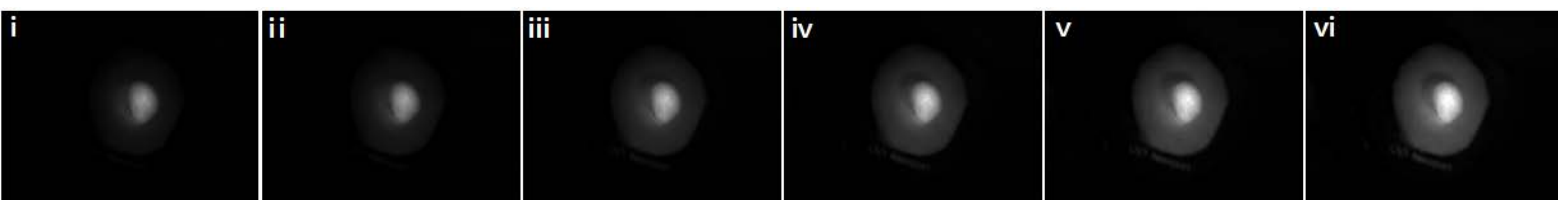

(c)

Figure 10. Short-pass filter is applied to 740 (a), 760 (b), 780 (c) nm excitation light and surgical light, and then NIR fluorescence imaging acquires (i: in case of $0.85 \mathrm{~mW} / \mathrm{cm}^{2}$; ii: in case of $1.38 \mathrm{~mW} / \mathrm{cm}^{2}$; iii: in case of $2.00 \mathrm{~mW} / \mathrm{cm}^{2}$; iv: in case of $2.47 \mathrm{~mW} / \mathrm{cm}^{2}$; v: in case of $3.28 \mathrm{~mW} / \mathrm{cm}^{2}$; vi: in case of $3.66 \mathrm{~mW} / \mathrm{cm}^{2}$ of surgical light output power).

that each contrast was in value from 0.55 to 0.8 and that it is possible to distinguish the background from the fluorescence at $0.85 \mathrm{~mW} / \mathrm{cm}^{2}$ power of surgical light when the short-pass filter referred to the light source and the surgical light.

\section{Conclusions}

In this paper, we have suggested that LEDs as the excitation light, the interior light and surgical light can degrade light source and the external.

To analyze influence of the excitation light, the interior light and surgical light as optical noise factor, we acquired and compared fluorescence images by using the ICG and NIR fluorescence imaging system under various experimental conditions such as no light, interior light and surgical light.

An experiment was carried out by using LEDs with center wavelength of 740, 760 and $780 \mathrm{~nm}$ as the excitation light source.

From measured results of spectrum and intensity of the excitation light source, the interior light and the surgical light with review of the optical noise occurrence factor, we could confirmed that the optical noise is generated because of the overlapping between wavelength band of the optical noise factors and wavelength band of fluorescence signal. To solve the optical noise problem, we applied the short-pass filter to optical noise factors.

We used the short-pass filter which has cut-off edge at $775 \mathrm{~nm}$ wavelength to minimize influence by optical characteristics of the optical factors such as intensity decrease.

We could confirm that contrast of fluorescence images improved $49 \%, 56 \%$ and $66 \%$ by using the short-pass filter as compared with contrast of fluorescence imaging in case of no short-pass filter.

\section{Discussion}

In research results of other groups, the LED excitation light source with center wavelength of $760 \mathrm{~nm}$ or $770 \mathrm{~nm}$ was considered as an optimal light source in case of ICG based on NIR signal detection [23]. However, after application of short-pass filter in our research results, we could confirm that NIR fluorescence imaging with improved fluorescence signal and contrast is possible by using LED excitation light source with center wavelength of $780 \mathrm{~nm}$. Also, we demonstrated that the excitation light source, interior light and surgical light affect seriously as optical noise factors in fluorescence imaging and that the application of the short-pass can make free from restraint of fluorescence imaging environment in performing the fluorescence imaging. 


\section{Acknowledgements}

This work was supported by the National Research Foundation of Korea (NRF) funded by the Ministry of Science, ICT \& Future Planning (2013-035981).

\section{References}

[1] Lee, B.-I., Kim, H.S., Jeong, H.J., Lee, H.J., Moon, S.M., Kwon, S.Y., Choi, E.S., Jeong, S.Y., Bom, H.S. and Min, J.J. (2009) Development of Optical Molecular Imaging System for the Acquisition of Bioluminescence Signals from Small Animals. Nuclear Medicine and Molecular Imaging, 43, 344-351.

[2] Leblond, F., Davis, S.C., Valdés, P.A. and Pogue, B.W. (2010) Pre-Clinical Whole-Body Fluorescence Imaging: Review of Instruments, Methods and Applications. Journal of Photochemistry and Photobiology B: Biology, 98, 77-94. http://dx.doi.org/10.1016/j.jphotobiol.2009.11.007

[3] Kim, D.E. (2006) Molecular Optical Imaging in Neuroscience. Journal of the Korean Neurological Association, 24, 101-105.

[4] Alander, J.T., Kaartinen, I., Laakso, A., Pätilä, T., Spillmann, T., Tuchin, V.V., Venermo, M. and Välisuo, P. (2012) A Review of Indocyanine Green Fluorescent Imaging in Surgery. Journal of Biomedical Imaging, 2012, 1-26. http://dx.doi.org/10.1155/2012/940585

[5] Ntziachristos, V. (2006) Fluorescence Molecular Imaging. Annual Review of Biomedical Engineering, 8, 1-33. http://dx.doi.org/10.1146/annurev.bioeng.8.061505.095831

[6] Shin, I.H., Kim, S.K., Eom, J.B., Park, J.S., Park, H.J., Park, I.K. and Lee, B.-I. (2013) Novel Imaging System for Positioning of the Indocyanine Green (ICG) Target; Visible Projection of the Near-Infrared Fluorescence Image. Journal of Biomedical Science and Engineering, 6, 896-900. http://dx.doi.org/10.4236/jbise.2013.69109

[7] Shin, I.H., Eom, J.B., Park, J.S., Park, H.J. and Lee, B.-I. (2014) Optical Probe for Near-Infrared (NIR) Fluorescence Signal Detection with High Optical Performance and Thermal Stability. Journal of Biomedical Science and Engineering, 7, 792-798. http://dx.doi.org/10.4236/jbise.2014.710078

[8] Gioux, S., Choi, H.S. and Frangioni, J.V. (2010) Image-Guided Surgery Using Invisible Near-Infrared Light: Fundamentals of Clinical Translaton. Molecular Imaging, 9, 237-255.

[9] Frangioni, J.V. (2003) In Vivo Near-Infrared Fluorescence Imaging. Current Opinion in Chemical Biology, 7, 626-634. http://dx.doi.org/10.1016/j.cbpa.2003.08.007

[10] Boddington, S.E., Henning, T.D., Jha, P., Schlieve, C.R., Mandrussow, L., DeNardo, D., Bernstein, H.S., Ritner, C., Golovko, D., Lu, Y., Zhao S. and Daldrup-Link, H.E. (2010) Labeling Human Embryonic Stem Cell-Derived Cardiomyocytes with Indocyanine Green for Noninvasive Tracking with Optical Imaging: An FDA-Compatible Alternative to Firefly Luciferase. Cell Transplantation, 19, 55-65. http://dx.doi.org/10.3727/096368909X478579

[11] Kongmire, M.R., Gunn, A.J., Morgan, N.Y., Smith, P.D., Pohida, T.J., Koyama, Y., Kobayashi, H. and Choyke, P.L. (2007) Real-Time Fluorescence-Enhanced Imaging as an Aid to Surgery in Ovarian Cancer. IEEE Journal of Selected Topics in Quantum Electronics, 13, 1602-1609. http://dx.doi.org/10.1109/JSTQE.2007.910998

[12] Keereweer, S., Kerrebijn, J.D.F., van Driel, P.B.A.A., Xie, B., Kaijzel, E.L., Snoeks, T.J.A., Que, I., Hutteman, M., van der Vorst, J.R., Mieog, J., Sven D., Vahrmeijer, A.L., van de Velde, C.J.H., Baatengurg de Jong, R.J. and Löwik, C.W.G.M. (2011) Optical Image-Guided Surgery_-Where Do We Stand? Molecular Imaging and Biology, 13, $199-207$. http://dx.doi.org/10.1007/s11307-010-0373-2

[13] Frangioni, J.V. (2008) New Technologies for Human Cancer Imaging. Journal of Clinical Oncology, 26, $4012-4021$. http://dx.doi.org/10.1200/JCO.2007.14.3065

[14] Marshall, M.V., Rasmussen, J.C., Tan, I.C., Aldrich, M.B., Adams, K.E., Wang, X., Fife, C.E., Maus, A., Smith, L.A. and Sevick-Muraca, E.M. (2010) Near-Infrared Fluorescence Imaging in Humans with Indocyanine Green: A Review and Update. Open Surgical Oncology Journal, 2, 12-25.

[15] Waseda, K., Ako, J., Hasegawa, T., Shimada, Y., Ikeno, F., Ishikawa, T., Demura, Y., Hatada, K., Yock, P.G., Honda, Y., Fitzgerald, P.J. and Takahashi, M. (2009) Intraoperative Fluorescence Imaging System for On-Site Assessment of Off-Pump Coronary Artery Bypass Graft. The Journal of the American College of Cardiology Cardiovascular Imaging, 2, 604-612. http://dx.doi.org/10.1016/j.jcmg.2008.12.028

[16] Choi, M.H., Choi, K.S., Ryu, S-W., Lee, J.W. and Choi, C.H. (2011) Dynamic Fluorescence Imaging for Multiparametric Measurement of Tumor Vasculature. Journal of Biomedical Optics, 16, Article ID: 046008. http://dx.doi.org/10.1117/1.3562956

[17] Sano, K., Mitsunaga, M., Nakajima, T., Choyke, P.L. and Kobayashi, H. (2012) In Vivo Breast Cancer Characterization Imaging Using Two Monoclonal Antibodies Activatably Labeled with Near Infrared Fluorophores. Breast Cancer Research, 14, R61. http://dx.doi.org/10.1186/bcr3167 
[18] Yokoyama, J., Ito, S., Ohba, S., Fujimaki, M. and Ikeda, K. (2011) A Novel Approach to Translymphatic Chemotherapy Targeting Sentinel Lymph Nodes of Patients with Oral Cancer Using Intra-Arterial Chemotherapy-Preliminary Study. Head \& Neck Oncology, 3, 1-6. http://dx.doi.org/10.1186/1758-3284-3-42

[19] Tanaka, E., Choi, H.S., Fujii, H., Bawendi, M.G. and Frangioni, J.V. (2006) Image-Guided Oncologic Surgery Using Invisible Light: Completed Pre-Clinical Development for Sentinel Lymph Node Mapping. Annals of Surgical Oncology, 13, 1671-1681. http://dx.doi.org/10.1245/s10434-006-9194-6

[20] Matsui, A., Lee, B.T., Winer, J.H., Kianzad, V. and Frangioni, J.V. (2009) Image-Guided Perforator Flap Design Using Invisible Near-Infrared Light and Validation with X-Ray angiography. Annals of Plastic Surgery, 63, 327-330. http://dx.doi.org/10.1097/SAP.0b013e318193493d

[21] Morita, Y., Sakaguchi, T., Unno, N., Shibasaki, Y., Suzuki, A., Fukumoto, K., Inaba, K., Baba, S., Takehara, Y., Suzuki, S. and Konno, H. (2013) Detection of Hepatocellular Carcinomas with Near-Infrared Fluorescence Imaging Using Indocyanine Green: Its Usefulness and Limitation. International Journal of Clinical Oncology, 18, 232-241. http://dx.doi.org/10.1007/s10147-011-0367-3

[22] Abe, H., Mori, T., Umeda, T., Tanaka, M., Kawai, Y., Shimizu, T., Cho, H., Kubota, Y., Kurumi, Y. and Tani, T. (2011) Indocyanine Green Fluorescence Imaging System for Sentinel Lymph Node Biopsies in Early Breast Cancer Patients. Surgery Today, 41, 197-202. http://dx.doi.org/10.1007/s00595-009-4254-8

[23] Yamamoto, M., Orihashi, K. and Sato, T. (2013) Intraoperative Indocyanine Green Imaging Technique in Cardiovascular Surgery. InTech, 81-97. 
Scientific Research Publishing (SCIRP) is one of the largest Open Access journal publishers. It is currently publishing more than 200 open access, online, peer-reviewed journals covering a wide range of academic disciplines. SCIRP serves the worldwide academic communities and contributes to the progress and application of science with its publication.

Other selected journals from SCIRP are listed as below. Submit your manuscript to us via either submit@scirp.org or Online Submission Portal.
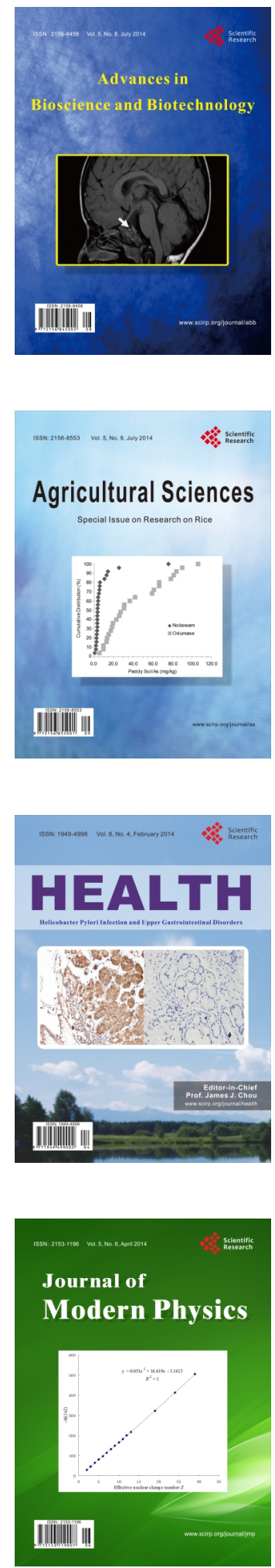
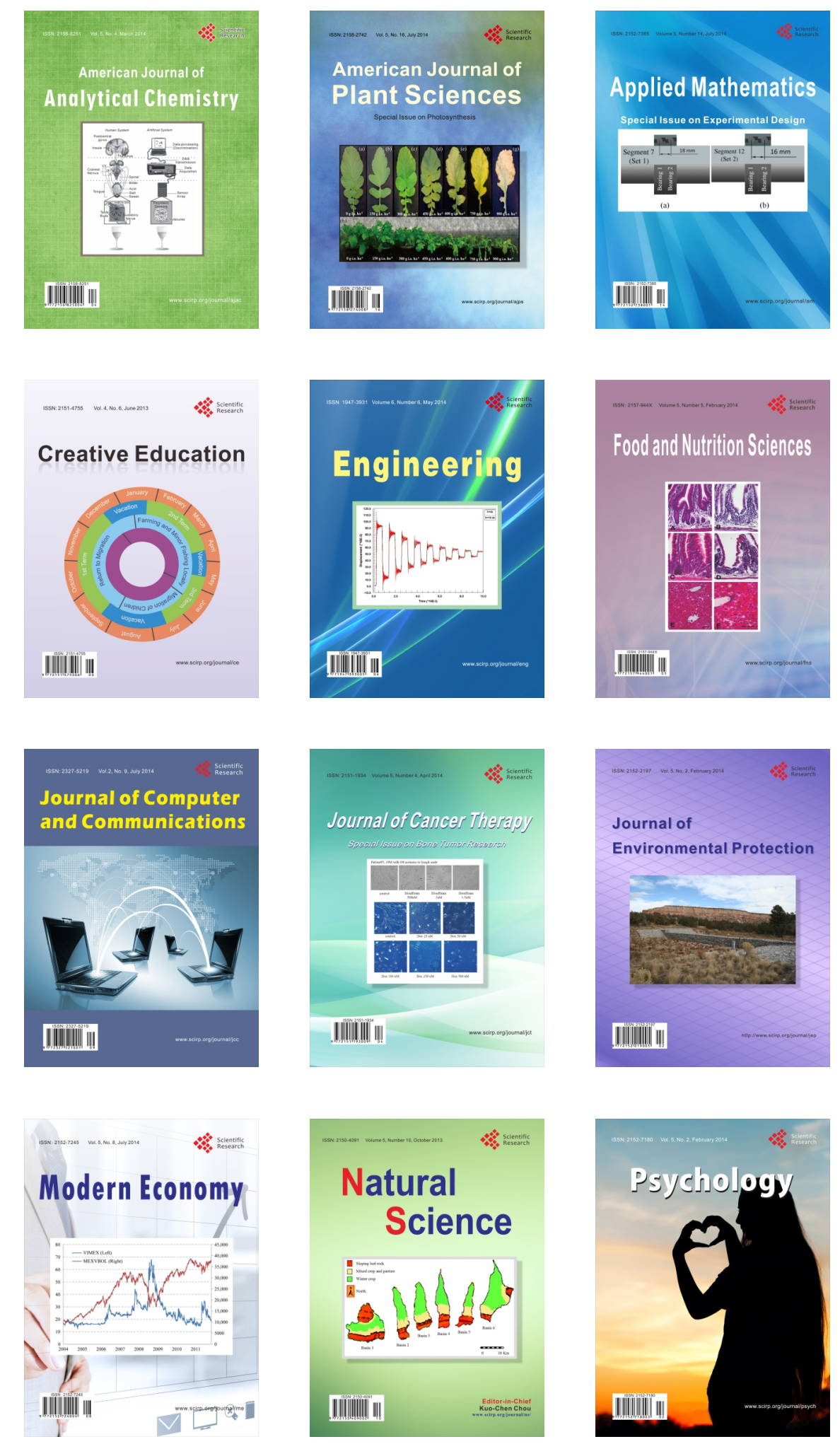